\title{
Períodos de Interferência das Plantas Daninhas na Cultura do ARroZ de Terras Altas. I - Cultivar IAC $202^{1}$
}

\author{
Periods of Weed Interference in the Upland Rice. I - Variety IAC 202
}

\author{
SILVA, M.R.M. ${ }^{2}$ e DURIGAN, J.C. ${ }^{3}$
}

\begin{abstract}
RESUMO - O trabalho foi conduzido com o objetivo de determinar os períodos de interferência e de controle das plantas daninhas na cultura do arroz de terras altas. Os experimentos foram instalados nos anos agrícolas de 2003/04 e 2004/05 em área experimental da Universidade Estadual Paulista, campus de Jaboticabal/SP, situado a $21^{\circ} 15^{\prime} 22^{\prime \prime}$ de latitude sul e $48^{\circ} 18^{\prime} 58^{\prime \prime}$ de longitude oeste. O cultivar utilizado foi o IAC 202 , semeado, respectivamente, em 18 de novembro de 2003 e 24 de novembro de 2004. O delineamento experimental foi em blocos ao acaso, com os tratamentos constituídos por períodos crescentes de controle ou de convivência das plantas daninhas com a cultura. Os períodos iniciais de controle ou de convivência após a emergência da cultura foram: 0-10, 0-20, 0-30, 0-40, 0-50, 0-60, 0-70 dias e 0-colheita. As principais plantas daninhas em 2003/04 foram Cyperus rotundus, Cenchrus echinatus, Digitaria spp. Echinochloa crus-galli e Brachiaria decumbens. No ano agrícola de 2004/05, destacaram-se Digitaria spp., C. echinatus, Raphanus raphanistrum e Alternanthera tenella. Considerando 5\% de tolerância na redução da produtividade do arroz nos anos agrícolas de 2003/04 e 2004/05, concluiu-se que os períodos anteriores à interferência (PAI) foram de 12 e 26 DAE, respectivamente; os períodos totais de prevenção à interferência (PTPI), de 40 e 42 DAE; e os períodos críticos de prevenção à interferência (PCPI), de 12 a 40 DAE e de 26 a 42 DAE, respectivamente.
\end{abstract}

Palavras-chave: competição, Oryza sativa, período crítico.

\begin{abstract}
This work was carried out to evaluate weed interference periods in upland rice during two growth seasons (2003/2004 and 2004/2005) in an experimental area owned by Universidade de São Paulo - UNESP, Jaboticabal/SP located at 21 $11^{\prime} 22^{\prime \prime}$ South latitude and $48^{\circ} 18^{\prime} 58^{\prime \prime}$ West longitude, using the rice cultivar IAC 202, sown on November18, 2003 and November, 24, 2004. The experimental design was randomized blocks, and the treatments consisted of increasing periods of control or coexistence with the culture. The initial periods of control or weed coexistence after culture emergence were: $0-10 ; 0-20 ; 0-30 ; 0-40$; O-50; 0-60; 0-70; O-harvest. The main weeds in 2003/04 were C. rotundus, C. echinatus, Digitaria spp., E. crusgalli and B. decumbens. In 2004/2005, Digitaria spp., C. echinatus, $\boldsymbol{R}$. raphanistrum and $\boldsymbol{A}$. tenella were identified. Considering $5 \%$ of tolerance in rice yield reduction during the two growth seasons (2003/2004 and 2004/2005), it was concluded that the periods prior to interference were 12 and 26 days after emergence (DAE); total periods of interference prevention, were 40 and $42 \mathrm{DAE}$ and critical periods of interference prevention, between 12 and $40 \mathrm{DAE}$ and 26 and $42 \mathrm{DAE}$, respectively.
\end{abstract}

Keywords: Oryza sativa, competition, critical period.

Recebido para publicação em 10.4.2006 e na forma revisada em 10.11.2006.

Parte da tese de doutorado do primeiro autor apresentada à UNESP - campus de Jaboticabal.

2 Doutoranda em Produção Vegetal da FCAV/UNESP, bolsista FAPEMA, <rmalheir@ fcav.unesp.br>; ${ }^{3}$ Prof. Adjunto do Departamento de Fitossanidade da FCAV-UNESP, 14884-900 Jaboticabal-SP. 


\section{INTRODUÇÃO}

As plantas daninhas constituem um dos fatores que mais influenciam o crescimento, $\mathrm{o}$ desenvolvimento e a produtividade da cultura do arroz de terras altas, pois competem por luz, nutrientes e água, o que se reflete na redução quantitativa e qualitativa da produção, além de aumentarem os custos operacionais de colheita, secagem e beneficiamento dos grãos.

A intensidade da interferência da comunidade infestante sobre as plantas do arroz de terras altas normalmente é medida pelos efeitos negativos sobre a produtividade, cujos valores são bastante variáveis, pois dependem de fatores ligados à cultura, à comunidade infestante e ao ambiente (Pitelli \& Durigan, 1983). Há diversos relatos de queda na produção de grãos, em função dessas variáveis, que atingem 56 a 71\% (Domingues, 1981), 60\% (Pitelli, 1981), 82\% (Diarra et al., 1985), 92\% (Castro \& Almario, 1992) e 96\% (Alcântara \& Carvalho, 1985).

Dentre os vários fatores que alteram o balanço de interferência entre a cultura e a comunidade infestante, destaca-se o período em que a comunidade infestante e as plantas cultivadas estão disputando os recursos do ambiente comum. Pitelli \& Durigan (1984) propuseram os conceitos de período anterior à interferência (PAI), período total de prevenção à interferência (PTPI) e período crítico de prevenção à interferência (PCPI). O PAI é conceituado como o período, a partir da emergência ou do plantio, em que a cultura pode conviver com a comunidade infestante antes que a sua produtividade ou outras características sejam alteradas negativamente. O PTPI é o período, a partir da emergência ou do plantio, em que a cultura deve ser mantida livre da presença da comunidade infestante, para que sua produtividade, qualidade da produção ou outras características não sejam alteradas negativamente. Como PCPI entende-se o período em que o controle da vegetação infestante deve ser realizado obrigatoriamente, situandose entre os limites superiores do PAI e do PTPI.

No arroz de terras altas, vários autores propuseram períodos críticos de interferência situados entre 20 e 50 dias após a emergência da cultura (Burga \& Tozani, 1980; Silveira Filho et al., 1984; Alcântara \& Carvalho, 1985).
Entre os critérios adotados por esses autores para definir o período crítico de interferência na cultura foram utilizados os testes de comparação de médias, que, segundo Spadotto et al. (1994), não são estatisticamente apropriados ao caso e aceitam, por vezes, grandes perdas na produtividade. Objetivou-se neste trabalho a determinação do Período Anterior à Interferência (PAI) e do Período Total de Prevenção à Interferência (PTPI) da comunidade infestante na produtividade do arroz de terras altas.

\section{MATERIAL E MÉTODOS}

O experimento foi instalado e conduzido em dois anos agrícolas (2003/04 e 2004/05), na área experimental do campus da UNESP de Jaboticabal-SP, situada a $21^{\circ} 15^{\prime} 22^{\prime \prime}$ de latitude sul e $48^{\circ} 18^{\prime} 58^{\prime \prime}$ de longitude oeste, com altitude aproximada de $600 \mathrm{~m}$, sobre Latossolo Vermelho, eutrófico típico, de textura argilosa, com topografia suavemente ondulada e boa drenagem (Andrioli \& Centurion, 1999). O cultivar de arroz foi o IAC 202, recomendado para o Estado de São Paulo por apresentar alta produtividade de grãos ( $\left.\mathrm{kg} \mathrm{ha}^{-1}\right)$ e estar adaptado às condições edafoclimáticas. Esse cultivar apresenta ciclo médio de maturação e florescimento de 120 e 87 dias, respectivamente, mas pode haver variações, principalmente em virtude da época de semeadura. A sua altura média é de $87 \mathrm{~cm}$, sendo considerado de porte baixo e com boa capacidade de perfilhamento (Bastos, 2000). Apresenta como características morfológicas folhas pequenas, estreitas e relativamente eretas. O preparo do solo foi o convencional, com aração e duas gradagens. A adubação e a semeadura foram mecanizadas e em uma única operação. Nos dois anos agrícolas, utilizaram-se na adubação $300 \mathrm{~kg} \mathrm{ha}{ }^{-1}$ da fórmula 4-14-8. As semeaduras foram realizadas em 18 de novembro de 2003 e 24 de novembro de 2004, respectivamente. A densidade de semeadura, nos dois anos agrícolas, foi de 90 sementes por metro linear de sulco. Para adubação em cobertura, utilizaram-se $60 \mathrm{~kg} \mathrm{ha}^{-1}$ de $\mathrm{N}$ aplicado no período da diferenciação das ramificações secundárias da panícula.

No primeiro ano agrícola foram semeadas, a lanço e em toda a área, sementes (500 g) de cada uma das plantas daninhas Digitaria spp., 
E. crus-galli, B. decumbens e Eleusine indica, a fim de garantir a infestação na área experimental. No segundo ano não se realizou esse procedimento, contando-se com o banco de sementes constituído. Foi usada irrigação por aspersão, sempre que necessário, com consumo de $800 \mathrm{~mm}$ e $2.000 \mathrm{~mm}$ de água para os anos agrícolas de 2003/04 e 2004/05, respectivamente. O delineamento experimental utilizado foi em blocos ao acaso, com dezesseis tratamentos e quatro repetições. As parcelas foram constituidas por sete linhas de cinco metros de comprimento, com espaçamento de 0,45 m. A área útil para avaliação foi constituída das três linhas centrais e teve como bordaduras duas linhas de plantio de cada lado e meio metro de cada uma das extremidades, perfazendo $5,40 \mathrm{~m}^{2}$. Foram constituídos dois grupos de tratamentos: um com o controle e outro com a convivência das plantas daninhas em períodos crescentes do início do ciclo da cultura do arroz, a partir da emergência. Após o final de cada período de controle, permitiu-se que as plantas daninhas crescessem livremente. No outro grupo, após o término de cada período inicial de convivência foi realizado o controle das plantas daninhas até a colheita, com capinas a cada dez dias. Os períodos iniciais de controle ou de convivência após a emergência da cultura foram: 0-10, 0-20, 0-30, 0-40, 0-50, 0-60, 0-70 dias e 0-colheita. Nas parcelas testemunhas, o mato permaneceu durante todo o ciclo ou então foi controlado em todo o período, até a colheita.

As avaliações da densidade e da matéria seca das plantas daninhas foram realizadas ao final de cada período de convivência, nos respectivos tratamentos; e, na colheita, para os tratamentos com períodos iniciais controlados. Essas avaliações foram feitas com o lançamento aleatório de retângulo metálico de $0,5 \times 0,2 \mathrm{~m}$, por três vezes, na área útil de cada parcela. As partes aéreas das plantas daninhas foram coletadas e separadas por espécie, determinando-se os valores de densidade e massa seca. A massa seca foi obtida pela secagem em estufa com ventilação forcada de ar, a $70{ }^{\circ} \mathrm{C}$, até atingir massa constante. Os dados foram submetidos à análise de regressão, cujos critérios de escolha foram baseados no valor do coeficiente de determinação $\left(\mathrm{R}^{2}\right)$, na significância da análise de variância da regressão e no fenômeno biológico.
A cultura foi colhida manualmente na área útil de cada parcela e, depois de passar por trilhadeira mecânica, a produção foi quantificada. Os dados de produtividade, padronizados para 13\% de umidade e expressos em $\mathrm{kg} \mathrm{ha}^{-1}$, foram submetidos à análise de regressão pelo modelo sigmoidal de Boltzmann, adaptado por Kuva et al. (2000). Este modelo obedece a seguinte equação:

$\mathrm{Y}=\mathrm{A}_{2}+\left\{\left(\mathrm{A}_{1}-\mathrm{A}_{2}\right) /(1+\exp [(\mathrm{x}-\mathrm{xo}) / \mathrm{dx}]\}, \mathrm{em}\right.$ que $\mathrm{Y}$ é a produtividade estimada do arroz, em kg ha-1; $\mathrm{A}_{1}$, a produção máxima estimada, obtida nas parcelas mantidas no limpo durante todo o ciclo; $A_{2}$, a produção mínima estimada obtida nas parcelas mantidas com mato durante todo o ciclo; $\mathrm{x}$, limite superior considerado do período de convivência ou controle; Xo, limite superior do período de convivência ou controle que corresponde ao valor intermediário entre a produção máxima e a mínima; e dx, parâmetro que indica a velocidade de perda ou ganho de produção (tg D no ponto Xo).

Com base nas equações de regressão, foram determinados os períodos de interferência das plantas daninhas para os níveis arbitrários de tolerância de 2, 5 e 10\% de redução na produtividade do arroz, em relação ao tratamento mantido na ausência das plantas daninhas.

\section{RESULTADOS E DISCUSSÃO}

\section{Comunidade Infestante}

Nas avaliações da comunidade infestante da cultura do arroz (cv. IAC 202) feitas ao final dos períodos de convivência, no ano agrícola de 2003/04, foram encontradas 26 espécies de plantas daninhas, pertencentes a 14 famílias botânicas. As famílias que mais se destacaram em número de espécie foram: Poaceae (23,08\%), Amaranthaceae (11,54\%), Asteraceae (7,69\%), Euphorbiaceae (7,69\%), Malvaceae $(7,69 \%)$ e Solanaceae $(7,69 \%)$. No ano agrícola de 2004/05, o número de espécies da comunidade infestante foi menor (20 espécies) em comparação com o do ano anterior. As espécies pertenceram a dez famílias botânicas, cujos destaques foram Poaceae (30\%), Asteraceae (15\%), Amaranthaceae (15\%) e Malvaceae (10\%). O elevado percentual para a família Poaceae, nos dois anos, pode ser explicado pela semeadura a lanço realizada no primeiro ano agrícola. 
As densidades populacionais das comunidades infestantes ao final dos períodos iniciais de convivência com a cultura, para os anos agrícolas de 2003/04 e 2004/05, estão representadas na Figura 1. De acordo com a equação sigmoidal de Boltzmann, ocorreu decréscimo acentuado dos 30 aos 70 DAE no ano agrícola de 2003/04. Isso decorreu da significativa mortalidade das plantas em função da competição pelos recursos do meio. Segundo Radosevich et al. (1997), à medida que aumenta a densidade e ocorre o desenvolvimento das plantas daninhas, especialmente daquelas que germinaram e emergiram no início do ciclo da cultura, intensifica-se a competição inter e intra-específica, de modo que as plantas daninhas mais altas e desenvolvidas tornam-se dominantes, ao passo que as menores são suprimidas ou morrem. Nesse ano agrícola, constatou-se uma densidade máxima aos 30 dias após a emergência (DAE) da cultura que correspondeu a 356 plantas $\mathrm{m}^{-2}$ e novo fluxo de emergência durante o período da colheita. No ano agrícola de 2004/05, conforme equação sigmoidal de Boltzmann, o decréscimo no número de indivíduos da comunidade infestante ocorreu no período de 30 a 50 DAE, em face da competição intra e interespecífica, destacando-se também o sombreamento imposto pelas plantas cultivadas. Após 50 DAE, a densidade manteve-se constante até os 70 DAE, verificando-se uma densidade máxima aos 10 DAE, com 178 plantas $\mathrm{m}^{-2}$.

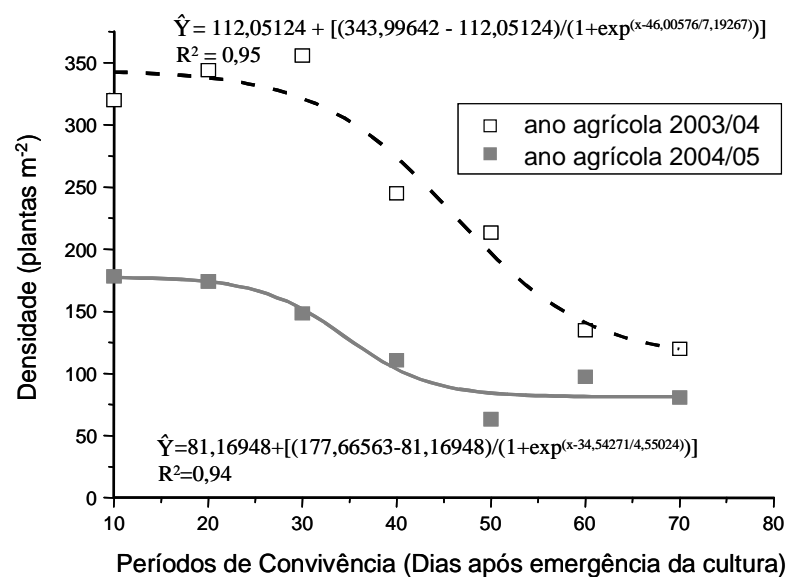

Figura 1 - Valores quantificados (pontos) e estimados pela equação sigmoidal de Boltzmann (curvas) para a densidade de plantas da comunidade infestante, em função dos períodos iniciais de convivência com o arroz (cv. IAC 202), nos anos agrícolas de 2003/04 e 2004/05. Jaboticabal-SP.
Na Figura 2 são apresentados os resultados de massa seca acumulada pela comunidade infestante, em função dos períodos iniciais de convivência, nos anos agrícolas de 2003/04 e 2004/05. Conforme as equações de Boltzmann, a massa seca da comunidade infestante, em ambos os anos, foi crescente até os 70 DAE. No primeiro ano, a massa seca foi mais elevada em relação ao segundo, porém na colheita o valor obtido foi menor, correspondendo a 920,00 $\mathrm{g} \mathrm{m}^{-2}$, enquanto no segundo ano foi de 1428,33 $\mathrm{g} \mathrm{m}^{-2}$. Segundo Pitelli (1985), em baixas densidades, o potencial de interferência de cada indivíduo pode se manifestar com maior intensidade.

No ano agrícola de 2003/04, as plantas daninhas mais importantes em termos numéricos, na comunidade infestante, foram: C. rotundus, C. echinatus, Digitaria spp., E. crus-galli e B. decumbens (Figura 3a). Observa-se que $C$. rotundus apresentou elevada densidade até os 50 DAE, quando sofreu redução drástica. Isso pode ser explicado pela sua emergência antes das plântulas de arroz, com forte brotação e crescimento inicial vigoroso. A redução ocorreu devido à competição com as outras espécies, sobretudo por luz, incluindo nessa assertiva o próprio sombreamento da cultura. A elevada densidade de C. rotundus não produziu aumentos substanciais na massa seca da comunidade infestante (Figura 3b). Após os 50 DAE, E. crus-galli

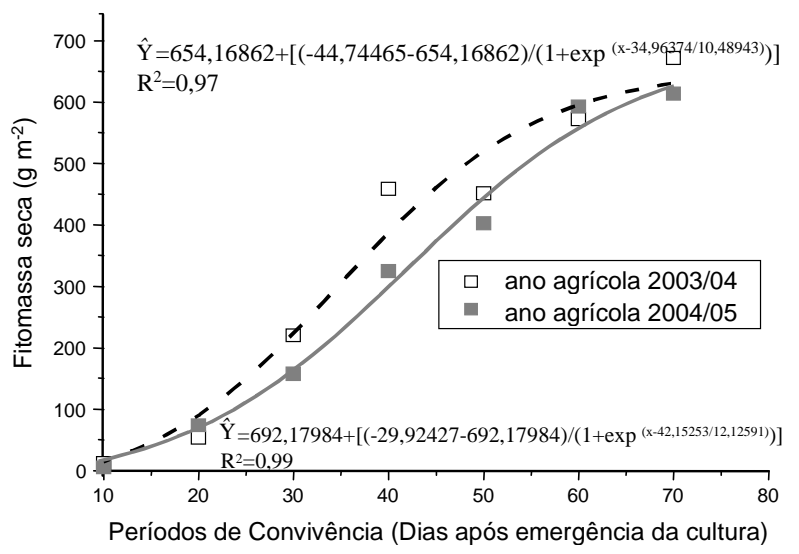

Figura 2 - Valores quantificados (pontos) e estimados pela equação sigmoidal de Boltzmann (curvas) para massa seca acumulada pela comunidade infestante, em função dos períodos iniciais de convivência com o arroz (cv. IAC 202), nos anos agrícolas de 2003/04 e 2004/05. Jaboticabal-SP. 
assumiu maior relevância em densidade até os 70 DAE. Foi ultrapassada na colheita por B. decumbens e Digitaria spp., ambas com densidades de 67,0 plantas $\mathrm{m}^{-2}$, e também por C. echinatus, com 35,8 plantas $\mathrm{m}^{-2}$. Devido ao aumento na densidade de $B$. decumbens no final do ciclo da cultura, ocorreu aumento na sua massa, para 208,03 $\mathrm{g} \mathrm{m}^{-2}$, como pode ser visto na Figura 3b. Para Digitaria spp., o acréscimo na massa seca foi menor: $143,53 \mathrm{~g} \mathrm{~m}^{-2}$. Isso indica que $B$. decumbens foi a espécie mais competitiva, por época de colheita, no ano agrícola de 2003/04. No final do ciclo da cultura, em 2004, foram constatadas apenas quatro principais espécies de plantas daninhas (C. echinatus, Digitaria spp., E. crus-galli e B. decumbens), que corresponderam a $87,01 \%$ da densidade e $75,98 \%$ da massa seca total da comunidade infestante.
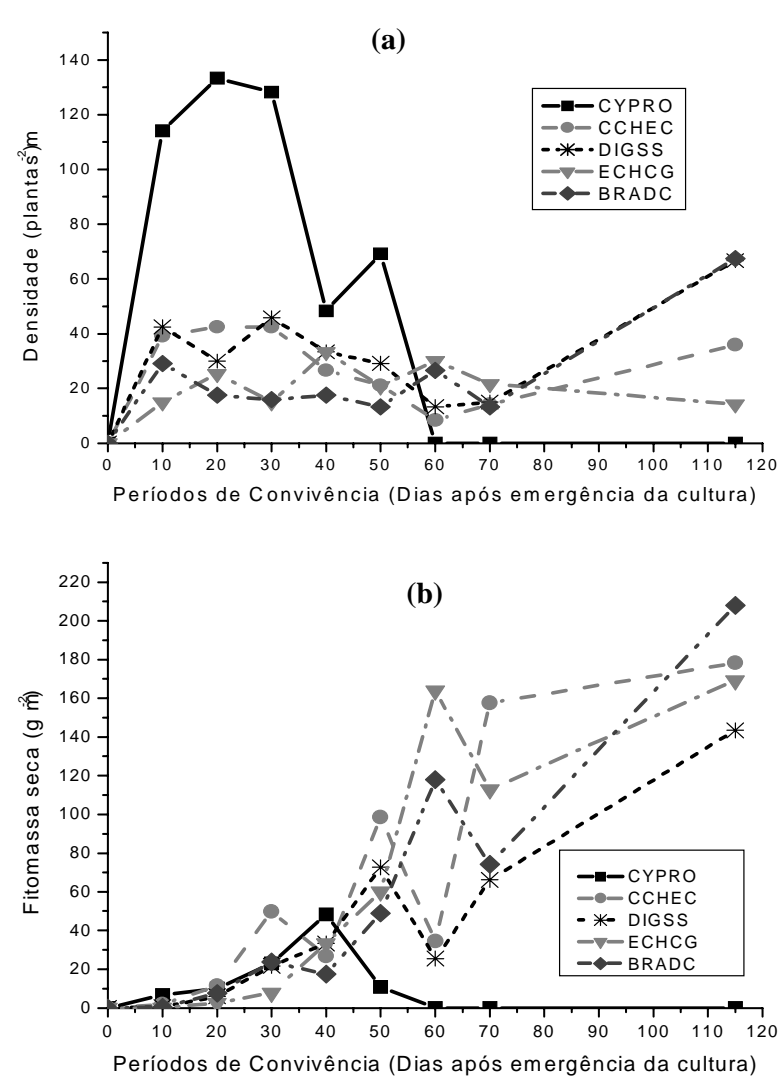

Figura 3 - Densidade (a) e massa seca (b) das principais plantas daninhas da comunidade infestante ao final dos períodos iniciais de convivência com o arroz (cv. IAC 202), no ano agrícola de 2003/04. Jaboticabal-SP.
Segundo Cobucci et al. (2001), as espécies de plantas daninhas mais agressivas ao arroz de terras altas do Cerrado pertencem aos gêneros Brachiaria, Cenchrus, Digitaria, Commelina e Ipomoea. No gênero Brachiaria destacam-se as espécies B. plantaginea e B. decumbens. Esta última é uma planta perene que se reproduz por sementes e de forma vegetativa. A germinação das suas sementes é muito irregular, pois muitas apresentam dormência inicial, o que dificulta as medidas de controle, necessitando de herbicidas de efeito residual longo.

No ano agrícola de 2004/05, as principais espécies da comunidade infestante ao final dos períodos iniciais de convivência com a cultura foram: Digitaria spp., C. echinatus, $R$. raphanistrum e $A$. tenella (Figura 4a). Nesse ano agrícola, aos dez dias após emergência, a
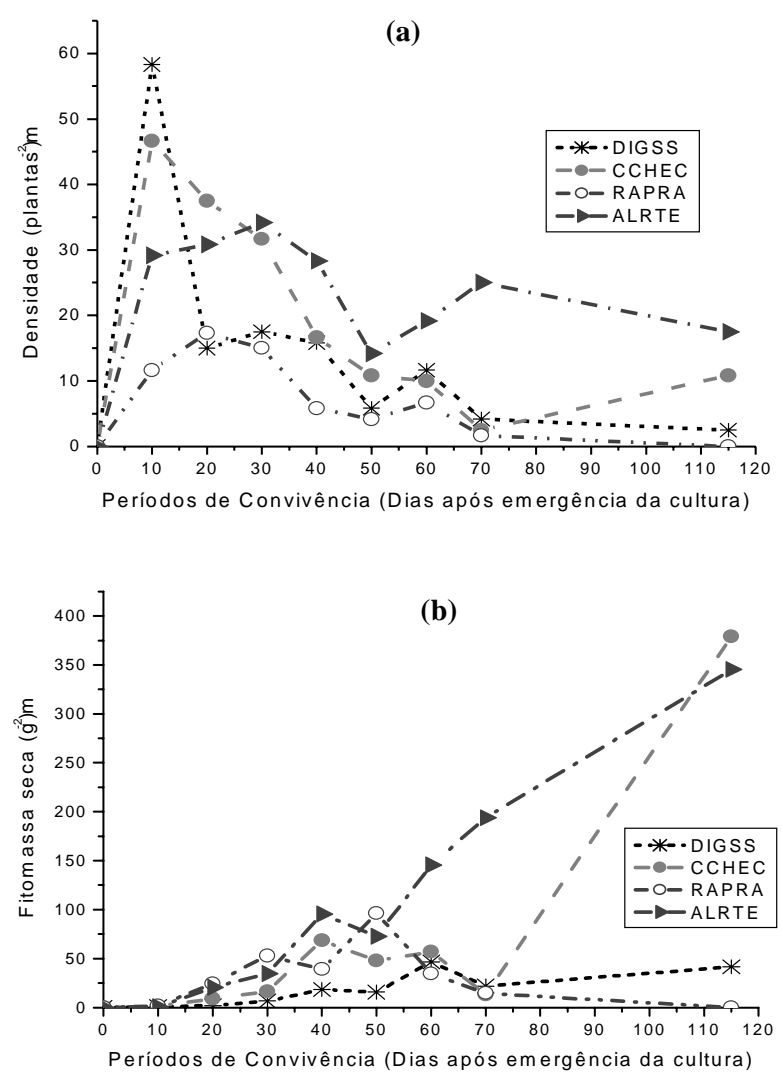

Figura 4 - Densidade (a) e massa seca (b) das principais plantas daninhas da comunidade infestante ao final dos períodos iniciais de convivência com o arroz (cv. IAC 202), no ano agrícola de 2004/05. Jaboticabal-SP.

Planta Daninha, Viçosa-MG, v. 24, n. 4, p. 685-694, 2006 
principal planta daninha foi Digitaria spp., com densidade de 58,3 plantas $\mathrm{m}^{-2}$. Após esse período, houve decréscimo acentuado, atingindo 15 plantas $\mathrm{m}^{-2}$, que se manteve até os $40 \mathrm{DAE}$, quando ocorreu nova redução. $\mathrm{Na}$ última avaliação da comunidade infestante, a sua densidade foi de 2,5 plantas $\mathrm{m}^{-2}$. Outra espécie que se destacou aos $10 \mathrm{DAE}$ foi $C$. echinatus, cuja densidade alcançou 46,7 plantas $\mathrm{m}^{-2}$, reduzindo com o desenvolvimento da cultura e voltando a ter acréscimos no final do ciclo. A. tenella, dos $30 \mathrm{DAE}$ até o final do ciclo da cultura, sobrepujou as outras espécies. Para a massa seca dessa espécie, os aumentos foram constantes ao longo do ciclo da cultura, atingindo $345,00 \mathrm{~g} \mathrm{~m}^{-2}$ na última avaliação da comunidade infestante (Figura 4b). Para C. echinatus também ocorreram acréscimos, porém menores em comparação com A. tenella, até os 70 DAE. Na última avaliação, essa planta daninha atingiu 379, $13 \mathrm{~g} \mathrm{~m}^{-2}$ (Figura 4b). Na colheita, em 2005, somente duas plantas daninhas destacaram-se: C. echinatus e A. tenella, correspondendo a 53,96\% da densidade e $50,72 \%$ da massa seca total da comunidade infestante. Segundo Kissmann \& Groth (1999), A. tenella é uma planta herbácea muito ramificada, de porte não muito elevado e, por isso, proporciona cobertura intensa ao solo.

As densidades populacionais da comunidade infestante na colheita, em função dos períodos iniciais de controle, nos dois anos estudados, estão apresentadas na Figura 5. No ano agrícola de 2003/04 ocorreu rápido decréscimo no número de plantas daninhas a partir dos 30 DAE, estabilizando-se, em baixo nível, até os 70 DAE. Significa que o aumento no período controlado não evitou que algumas plantas germinassem até o final do ciclo. Na testemunha sem controle de plantas daninhas, a densidade foi elevada, atingindo 212 plantas $\mathrm{m}^{-2}$, evidenciando a necessidade de controle inicial em anos de alta infestação. No ano agrícola de 2004/05, os decréscimos na densidade da comunidade infestante em função dos períodos iniciais de controle foram menos acentuados, ocorrendo a partir dos 30 até os 70 DAE. Nesse ano, a densidade foi menor na testemunha sem controle das plantas daninhas, atingindo 52,5 plantas $\mathrm{m}^{-2}$. No primeiro ano, apesar da infestação inicial maior, os períodos iniciais de controle tiveram efeito marcante sobre as densidades constatadas na colheita. Nesse caso, os fluxos de emergência da comunidade infestante foram mais concentrados no início do ciclo. No segundo ano, a germinação foi menor, porém constante, durante todo o período.

Os valores de massa seca acumulada pela comunidade infestante até a colheita, em função dos períodos iniciais de controle, em ambos os anos agrícolas encontram-se na Figura 6. De acordo com a equação sigmoidal de Boltzmann ajustada aos dados, a biomassa seca acumulada pela comunidade infestante foi decrescente com o aumento dos períodos de controle, para os dois anos. Os períodos crescentes de controle até os 70 DAE reduziram consideravelmente o acúmulo de massa seca pela comunidade infestante. O crescimento do cultivar IAC 202 também teve participação na complementação do controle, potencializando-o a partir dos $40 \mathrm{DAE}$, reduzindo o estabelecimento e o crescimento das plantas daninhas na área. Esses resultados coincidiram com os de Castro \& Almario (1992), que evidenciaram a necessidade de controle no início da cultura, em face do rápido crescimento das plantas daninhas, sobretudo gramíneas, e o lento desenvolvimento inicial das plantas de arroz. Enfatizaram ainda a necessidade de intervenções nos primeiros 20 a 30 dias após a emergência da cultura.

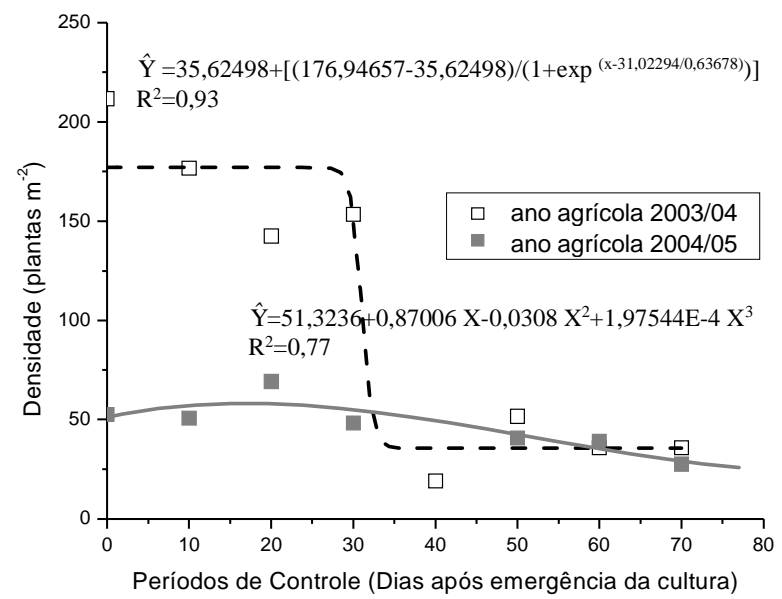

Figura 5 - Valores quantificados (pontos) e estimados pela equação sigmoidal de Boltzmann (curva tracejada) e pela equação cúbica (curva não tracejada) para a densidade de plantas da comunidade infestante na colheita, em função dos períodos iniciais de controle na cultura do arroz (cv. IAC 202), nos anos agrícolas de 2003/04 e 2004/05. Jaboticabal-SP. 


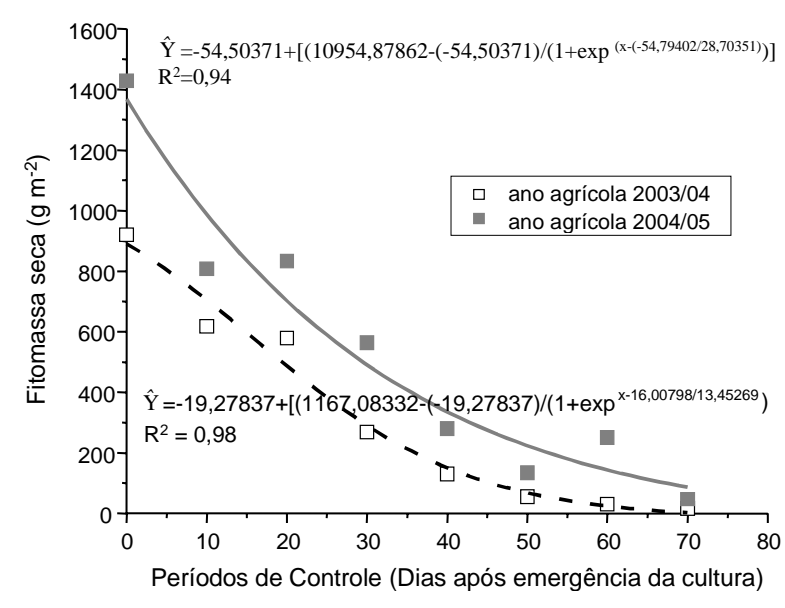

Figura 6 - Valores quantificados (pontos) e estimados pela equação sigmoidal de Boltzmann (curvas) para massa seca acumulada pela comunidade infestante na colheita, em função dos períodos iniciais de controle do arroz (cv. IAC 202), nos anos agrícolas de 2003/04 e 2004/05. Jaboticabal-SP.

\section{Produtividade do arroz (cv. IAC 202)}

Nas Figuras 7 e 8 são apresentadas as curvas de produtividades do arroz, ajustadas pelo modelo sigmoidal de Boltzmann, em função dos períodos de convivência ou de controle das plantas daninhas, nos anos de 2003/04 e 2004/05, respectivamente.

Na Tabela 1 estão apresentados os parâmetros da equação para a regressão dos dados de produtividade desse cultivar, em função dos períodos de interferência ou de controle das plantas daninhas, nos dois anos de estudo. Considerando-se uma perda de 5\% na produtividade desse cultivar no ano agrícola de 2003/04, a convivência começou a afetar a cultura aos 12 dias após a emergência (Figura 7), estendendo-se o necessário controle das plantas daninhas até os 40 dias após a emergência.

O período crítico de prevenção à interferência (PCPI) caracterizou-se pelo intervalo entre 12 e 40 dias após a emergência da cultura. No ano seguinte (2004/05), admitindo a mesma perda de 5\% (Figura 8), obteve-se PAI de 26 DAE e PTPI de 42 DAE. O PCPI, portanto, ficou entre 26 e 42 DAE. Verificou-se, então, para o cv. IAC 202, admitindo-se perda aceitável de 5\% nos dois anos agrícolas, uma diferença de 14 dias nos valores encontrados para o PAI. O valor foi menor em 2003/04 devido à maior pressão da comunidade infestante no início do ciclo, em razão da maior ocorrência de monocotiledôneas.

Segundo Pitelli (1985), quanto maior for a densidade da comunidade infestante, maior será a quantidade de indivíduos que disputam os recursos do meio e, portanto, mais intensa será a competição sofrida pela cultura. Além disso, espécies morfológica e fisiologicamente

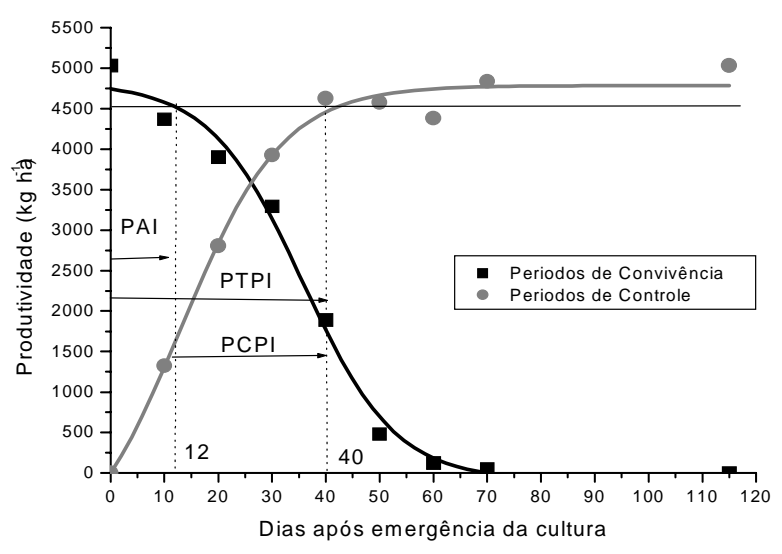

Figura 7 - Produtividade do arroz (cv. IAC 202) e ajuste dos dados pelo modelo sigmoidal de Boltzmann, em função dos períodos de controle e de convivência com as plantas daninhas, considerando-se uma perda de 5\%, no ano agrícola de 2003/04. Jaboticabal-SP.

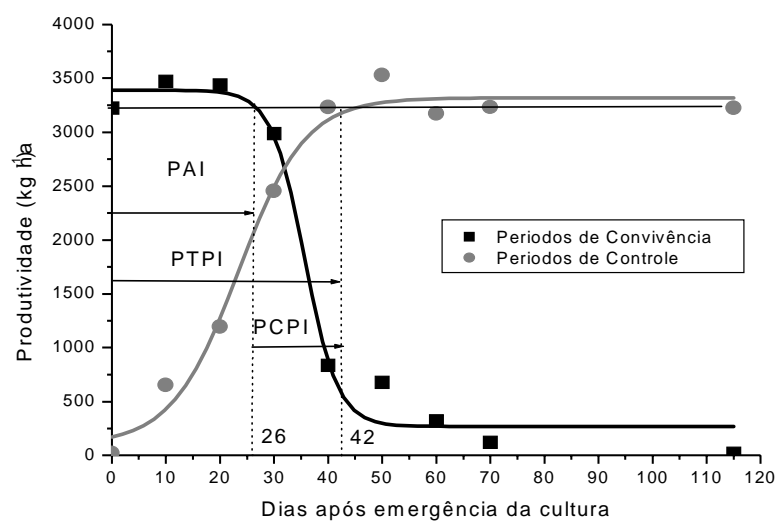

Figura 8 - Produtividade do arroz (cv. IAC 202) e ajuste dos dados pelo modelo sigmoidal de Boltzmann, em função dos períodos de controle e de convivência com as plantas daninhas, considerando-se uma perda de 5\%, no ano agrícola de 2004/05. Jaboticabal-SP. 
próximas apresentam exigências semelhantes em relação aos fatores de crescimento, tornando mais intensa a competição pelos fatores limitados no ambiente comum.

Em relação ao PTPI, a variação entre os dois anos agrícolas foi de apenas dois dias. Esse resultado ratifica a premissa de boa complementação do controle exercido pelas plantas de arroz após os 40 DAE. Esse período pode ser facilmente atendido pela utilização de cultivadores mecânicos ou satisfeito pelo efeito residual de um herbicida. Estudos conduzidos por Alcântara \& Carvalho (1985) com o cv. IAC 47 indicaram que o período de competição foi de 40 dias após a emergência, a contar da germinação do arroz. Burga \& Tozani (1980) verificaram, para cv. IAC 25, que o período crítico foi dos 30 aos 50 dias após emergência da cultura. Experimentos realizados no CNPAF determinaram que o controle das plantas daninhas deve ser efetuado, no máximo, até 30 DAE da cultura, quando ocorre deficiência hídrica (Silveira Filho et al., 1984). Portanto, verifica-se que para a cultura do arroz de terras altas existe uma variação nos períodos de controle ou de convivência decorrente de fatores como solo, clima, cultivar e espécies de plantas daninhas.
Na Tabela 2 são apresentadas as estimativas dos valores do limite superior dos períodos de interferência ou de controle das plantas daninhas, em função de três niveis de tolerância, na redução da produtividade do arroz, para os dois anos agrícolas. Admitindose $10 \%$ de redução na produtividade em 2003/ 04, o PAI foi de 17 DAE e o PTPI de 34 DAE. Reduzindo-se o nivel de tolerância para $2 \%$, o PAI passou para 7 DAE e o PTPI para 47 DAE. Portanto, para que a diminuição tolerada na produtividade do arroz mudasse de $2 \%$ para 10\% foi necessário acréscimo de dez dias no período de convivência. Para aumentar a produtividade de $90 \%$ para $98 \%$, foi necessário acréscimo de 13 dias no período de controle. Para redução de $2 \%$ na produtividade, no ano agrícola de 2004/05, o PAI foi de 24 DAE e o PTPI de 48 DAE. Aumentando-se o nível de tolerância para 10\%, o PAI passou para $29 \mathrm{DAE}$ e o PTPI para 37 DAE. Com o acréscimo do nível de tolerância de $2 \%$ para $10 \%$, verificouse ser necessário aumento de cinco dias no período de convivência, nesse ano. Contudo, para elevar a produtividade de 90\% para 98\%, foi necessário aumentar em 11 dias o período livre de interferência das plantas daninhas.

Tabela 1 - Parâmetros das equações sigmoidais de Boltzmann, ajustadas aos dados de produção, em função dos períodos de convivência ou controle das plantas daninhas na cultura do arroz (cv. IAC 202), em dois anos agrícolas. Jaboticabal-SP

\begin{tabular}{|c|c|c|c|c|}
\hline \multirow{2}{*}{ Parâmetro } & \multicolumn{2}{|c|}{$2003 / 04$} & \multicolumn{2}{|c|}{$2004 / 05$} \\
\cline { 2 - 5 } & Convivência & Controle & Convivência & Controle \\
\hline $\mathrm{A}_{1}$ & $4.820,10$ & $-876,12$ & $3.389,77$ & 101,40 \\
\hline $\mathrm{A}_{2}$ & $-94,16$ & $4.677,083$ & 269,51 & $3.318,61$ \\
\hline $\mathrm{X}_{0}$ & 35,69 & 13,90 & 35,66 & 23,42 \\
\hline $\mathrm{Dx}$ & 8,65 & 8,43 & 3,064 & 6,16 \\
\hline $\mathrm{R}^{2}$ & 0,992 & 0,991 & 0,986 & 0,986 \\
\hline Teste $\mathrm{F}$ & $330,0493^{* *}$ & $617,2555^{* *}$ & $204,1483^{* *}$ & $397,6615^{* *}$ \\
\hline
\end{tabular}

Tabela 2 - Variação do período anterior à interferência e do período total de prevenção à interferência da comunidade infestante sobre o arroz (cv. IAC 202), em função das porcentagens de redução de produtividade toleradas, em dois anos agrícolas. Jaboticabal-SP

\begin{tabular}{|c|c|c|c|c|c|c|c|c|}
\hline \multirow{2}{*}{$\begin{array}{c}\text { Período } \\
\text { de interferência }\end{array}$} & \multicolumn{4}{|c|}{ Porcentagem de redução-2003/04 } & \multicolumn{4}{c|}{ Porcentagem de redução-2004/05 } \\
\cline { 2 - 9 } & $2 \%$ & $5 \%$ & $10 \%$ & 2 a $10 \%$ & $2 \%$ & $5 \%$ & $10 \%$ & 2 a $10 \%$ \\
\hline PAI & 7 & 12 & 17 & 10 dias & 24 & 26 & 29 & 5 dias \\
\hline PTPI & 47 & 40 & 34 & 13 dias & 48 & 42 & 37 & 11 dias \\
\hline
\end{tabular}


A produtividade do cultivar na ausência total da interferência das plantas daninhas em 2003/04 foi de 5032,4 $\mathrm{kg} \mathrm{ha}^{-1}$, enquanto em 2004/05 foi de apenas $3223,98 \mathrm{~kg} \mathrm{ha}^{-1}$. Ocorreu, portanto, redução de $40 \%$ no segundo ano agrícola, apesar da menor infestação. Esse fato provavelmente ocorreu pela maior quantidade e boa distribuição das chuvas naturais, além da irrigação realizada, no período da diferenciação dos grãos, que começa aproximadamente 15 dias antes da floração (estádio mais sensível ao déficit hídrico). O florescimento desse cultivar ocorreu por volta dos 85 e 80 DAE, nos anos agrícolas de 2003/04 e 2004/05, respectivamente. No primeiro ano agrícola, 15 dias antes desse estádio fenológico, a quantidade de chuvas foi de $132 \mathrm{~mm}$, enquanto no segundo foi de apenas $34,2 \mathrm{~mm}$. Experimentos conduzidos por Fofana \& Rauber (2000) com arroz de terras altas na África não evidenciaram crescimentos na produção do segundo ano agrícola, em parte pela baixa pluviosidade durante o período, levando à redução na disponibilidade de nutrientes. Vários trabalhos relatam reduções da produção de arroz de um ano para outro, quando ele é cultivado no mesmo local. O "cansaço da terra", como é chamado pelos agricultores, pode ocorrer devido à ação de compostos alelopáticos produzidos pelas próprias plantas de arroz. Chou (1985) relatou uma série de experimentos para elucidar o motivo da redução da produção do arroz no segundo cultivo e o associou com a liberação de fitotoxinas pelas próprias plantas, que foram identificadas como ác. p-cumárico, p-hidroxibenzóico, siríngico, vanílico, o-hidroxifenilacético, felúrico, propiônico, acético e butírico.

A convivência com as plantas daninhas durante todo o ciclo ocasionou severa interferência, resultando em perdas de produtividade de 100 e $90 \%$ para os anos de 2003/04 e 2004/ 05 , o que ratifica a necessidade de um período de controle inicial que proporcione vantagens ao desenvolvimento da cultura e sua posterior complementação ao controle pelo sombreamento. Também evidencia baixa capacidade competitiva natural do cultivar utilizado, que apresenta porte baixo e folhas eretas. Com 5\% de tolerância na redução da produtividade do arroz nos anos agrícolas de 2003/04 e 2004/ 05, os períodos anteriores à interferência (PAI) foram de 12 e $26 \mathrm{DAE}$, respectivamente; os períodos totais de prevenção à interferência (PTPI), de 40 e 42 DAE; e os períodos críticos de prevenção à interferência (PCPI), de 12 a $40 \mathrm{DAE}$ e de 26 a $42 \mathrm{DAE}$, respectivamente.

\section{AGRADECIMENTOS}

À Fundação de Amparo à Pesquisa e ao Desenvolvimento Científico e Tecnológico do Estado do Maranhão (FAPEMA), pela concessão da bolsa de Aperfeiçoamento à doutoranda Maria Rosangela Malheiros Silva.

\section{LITERATURA CITADA}

AlCÂNTARA, E. N.; CARVALHO, D. A. Período de competição de plantas daninhas com arroz de sequeiro. Pesq. Agrop. Bras., v. 20, n. 5, p. 599-609, 1985.

ANDRIOLI, I.; CENTURION, J. F. Levantamento detalhado dos solos da Faculdade de Ciências Agrárias e Veterinárias de Jaboticabal. In: CONGRESSO BRASILEIRO DE CIÊNCIA DO SOLO, 27.,1999, Brasília. Anais... Brasília: Sociedade Brasileira da Ciência do Solo, 1999. p. 32.

BASTOS, C. R. IAC 202: Arroz de alta produtividade e qualidade para cultura de sequeiro. O Agronômico, v. 52, n. 1, p. 24-25, 2000.

BURGA, C. A; TOZANI, R. Competição de plantas daninhas com a cultura do arroz de sequeiro (Oryza sativa L.). Agronomia, v. 33, p. 23-32, 1980.

CASTRO, R. A.; ALMARIO, G. O. Efecto de la competencia de malezas gramíneas en el arroz (Oryza sativa L.). In: CONGRESO ASOCIATION LATINO AMERICANA DE

MALEZAS. Resume de trabajos... Vina Del Mar: Pontifícia Universidad Católica de Chile, 1992. p. 24.

COBUCCI, T.; RABELO, R. R.; SILVA, W. Manejo de plantas daninhas na cultura do arroz de terras altas na região dos Cerrados. Santo Antonio de Goiás: Embrapa Arroz e Feijão, 2001. (Circular Técnica/ Embrapa Arroz e Feijão, 42).

CHOU, C. H. Allelopathy in subtropical vegetation and soils in Taiwan. In: WALLER, G.R. (Ed.). Allelochemicals: role in agriculture and florestry. Washington: American Chemical Society, 1985. p. 102-117. (ACS Symposium Series, 330).

DIARRA, A.; SMITH JR, R. J.; TALBERT, R. E. Interference of red rice (Oryza sativa) with rice (O. sativa). Weed Sci., v. 33, n. 5, p. 644-649, 1985. 
DOMINGUES, E. P. Efeitos do espaçamento e fertilização nitrogenada em cobertura sobre as relações competitivas entre a cultura do arroz de sequeiro (Oryza sativa $\mathbf{L}$.) e a comunidade infestante. 1981. 75 f. Monografia (Trabalho de Graduação em Agronomia) - Universidade Estadual Paulista, Jaboticabal, 1981.

FOFANA, B.; RAUBER, R. Weed suppression ability of upland rice under low-input condition in West África. Weed Res., v. 40, n. 3, p. 271-280, 2000.

KISSMANN, K. G.; GROTH, D. Plantas infestantes e nocivas. 2.ed. São Paulo: BASF, 1999. 978 p.

KUVA, M. A. et al. Períodos de interferência das plantas daninhas na cultura da cana-de-açúcar. I - Tiririca. Planta Daninha, v. 18, n. 2, p. 241-251, 2000.

PITELLI, R. A. Competição por nutrientes entre a cultura do arroz e a comunidade infestante. Efeitos do espaçamento e da fertilização nitrogenada. 1981. $72 \mathrm{f}$. Tese (Doutorado em Agronomia) - Escola Superior de Agricultura “Luiz de Queiroz”, Piracicaba, 1981.

PITELLI, R. A. Interferência de plantas daninhas em culturas agrícolas. Inf. Agropec., v. 11, n. 129, p. 16-27, 1985.
PITELLI, R. A.; DURIGAN, J. C. Manejo das plantas daninhas na cultura do arroz de sequeiro. In: SIMPÓSIO SOBRE A CULTURA DO ARROZ DE SEQUEIRO, 1., 1983, Jaboticabal. Anais... Jaboticabal: FCAV/UNESP, 1983. p. 184-203.

PITELLI, R. A.; DURIGAN, J. C. Terminologia para períodos de controle e de convivência das plantas daninhas em culturas anuais e bianuais. In: CONGRESSO BRASILEIRO DE HERBICIDAS E PLANTAS

DANINHAS, 15., 1984, Belo Horizonte. Resumos... Belo Horizonte: SBHDE, 1984. p. 37.

RADOSEVICH, S. R.; HOLT, J.; GHERSA, C. Weed ecology: implications for management. 2.ed. New York: John Wiley \& Sons, 1997. 589 p.

SILVEIRA FILHO, A.; AQUINO, A. R. L.; SANTOS, A. B. Controle de plantas daninhas na cultura do arroz de sequeiro. Goiânia: EMBRAPA-CNPAF, 1984. 6 p. (Comunicado Técnico, EMBRAPA - CNPAF, 15).

SPADOTTO, C. A. et al. Determinação do período crítico para prevenção da interferência de plantas daninhas na cultura da soja: uso do modelo "Broken-Stick". Planta Daninha, v. 12, n. 2, p. 59-62, 1994. 